\title{
Editorial: Screendance Now
}

Harmony Bench, The Ohio State University

Simon Ellis, C-DaRE (Centre for Dance Research), Coventry University

Keywords: screendance, editorial, identity, culture

In the IJSD call for papers in May 2018, we wrote:

The first volume of IJSD asserted ... that "Screendance has not yet been invented." Volume 10 of IJSD presents an opportunity to reflect on screendance now. Where do we find ourselves as a field? ${ }^{1}$

It is not surprising then that many of the contributions in Volume 10 deal directly and indirectly with questions of screendance's identity. Whereas in Volume 5-a themed call on community and screendance ${ }^{2}$ - the contributions examined the ways in which we are drawn together as a community of artists and scholars, here in Volume 10, we see traces and evidence of a field morphing and adapting, continuing to question its own value and values, and drawing new and shifting boundaries around its identity. One of the founding principles of IJSD, which Doug Rosenberg has articulated so well, is that that field of screendance is capacious enough to include "any dance on any screen." ${ }^{3}$ While we have been at the helm of this journal, we have remained grounded in the histories and aesthetic practices of dance film, while also actively making space for dance in popular television, film, music video, and internet cultures. We have been gratified to support the explosion of dance across media platforms with the expansive focus of this journal.

Faced with the provocation that inaugurated IJSD — that screendance has not yet been invented-and our own call to consider screendance now, we find ourselves everunable to define just what it is that we study in this field. Any dance (but what counts as dance?) on any screen (what counts as screen?). As co-editors, we have delighted in this ambiguity, and have purposefully refused easy categorization. There is undoubtedly a desire by many screendance people to stabilize or know screendance; to be able to cordon off its edges. Maybe some of us even want to understand or know ourselves (and our practices) through the act of understanding the field of screendance and its disciplines. We want an identity that is legible to the institutions with(in) which we work. What do we imagine will be cleaned up if we might some day in the future agree on the limits and boundaries of screendance's identity, and the practices of which it is comprised? But there is also resistance to such knowability from within the screendance community, indeed if resistance has any value in a digital world: 
There is no resistance in a digital environment-only on or off. Anything inbetween is relegated to one or the other, anyway. We can't attenuate the digital. There is no volume knob. There are no knobs at all; there are only switches. In a digital media environment there is no resistance, only opposition.

- Douglas Rushkoff ${ }^{4}$

If this journal is not then an act of resistance, we understand it to embody a key paradox: that screendance's edges can never be identified, maintained, or claimed, and that these non-existent edges are in turn bound by these digital pages. That is, the presence of a journal in any field inevitably marks its boundaries. The desire to make sense of phenomena and things is powerful. A scholarly journal is in some way a means to make sense of a field. But it does this work while also responding to what the field is doing (or rather, what the people in the field are doing and submitting). At each step, we are responding to contributions subjectively and with desire; desire to make sense, to build a fence around the field of screendance. But, curiously, and most importantly, it is a fence that is shifting and porous; a fence that includes and distinguishes. There is no pattern here in this field of screendance, no identity, there is no thing or regularity to be seen. Nevertheless, that work of construction or imagination, of clustering around particular ideas, themes and senses, is valuable. It is cultural work. In the thousands of decisions that go into the writing of each submission, in the thousands of decisions that go into editing and publishing each volume, we are making and shaping the field as we ourselves are being made and shaped.

[Culture] shapes the minds of individuals as well. It's individual expression inheres in meaning making, assigning meanings to things in different settings on particular occasions. Meaning making involves situating encounters with the world in their appropriate culture contexts in order to know 'what they are about.'

- Jerome Bruner ${ }^{5}$

What then are the "appropriate culture contexts" for our field of screendance? Or, better still, which are the inappropriate contexts? The strength of any demarcation is that it helps us to express difference, but it also affords the danger of looking inwards and tribalism. If a culture "is the sum of all things about which humanity can choose to differ" ${ }^{\prime \prime}$ then how might the field of screendance-and all its recognisable and unrecognisable mangle of practices - continue to look outwards beyond what is known or understood? The time will always be ripe to increase the porosity of the edges of screendance practice and scholarship.

As we make way for a new editorial team, we feel a second paradox keenly: that even as we have embraced a broad concept for screendance, external pressures may impose a 
coherent identity on screendance that its practitioners and scholars have not chosen for themselves, or that the broad adoption of digital visual media will make our artistic and intellectual contributions moot. We are reminded of Hamish MacPherson's provocation in Volume 6 that perhaps there is no place for screendance because now every place is one of screendance:

... I only have to look around at my peers and see they are already making short films and putting them online, and these are part of their practice and their work as much as dancing and writing and talking and all kinds of things. So I wonder what place there is for screendance, with all its established forms and boundaries and requirements. How does it relate to ways that people are using video technology to capture and present and produce movement right now? Genuine question.

- Hamish MacPherson ${ }^{7}$

What does it even mean to speak of screendance now, when we carry screens everywhere with us, indeed, when we no longer seem able to escape our screens? We can imagine that the practices, disciplines, and people that are screendance are akin to what science historian Hans-Jörg Rheinberger refers to as an experimental system. He writes that:

Experimental systems don't come in isolation. As a rule, they are part of broader landscapes, or cultures of experimentation. They form ensembles with a patchwork structure. ${ }^{8}$

Screendance is unequivocally part of a broader patchwork of influences and culture; it works with and across ideas, practices, form, structures, tastes, and fashions. We (Harmony and Simon that is) see opportunities to look outwards in this multifarious (and experimental) collection or patchwork. The practice of writing to and about screendance is also able to reflect the "experimental goings-on", ${ }^{9}$ and we like to imagine that the writing in this volume represents a point of departure from conversations about what does or doesn't qualify as screendance-a time for screendance to understand the certainties of our past, our practices, and recognize (or reach outwards) into the uncertainties, and into future newness and difference. Ten volumes into this journal, we think we are only just starting to peer into the thickness of the world of screendance: its practices, ideas, writing, reflection, curiosities and concerns. What new or unaccounted for questions may yet be revealed in the work we are making, watching, and thinking and writing about? And will this work require that we let go of or reinvest in concepts of dance and screen for these questions to emerge?

In her book Cinema and Sensation (2007), Martine Beugnet draws attention to the aesthetics of sensation, where the materiality of a film is "given precedence over its expository and mimetic/realistic functions." ${ }^{10}$ She writes that to foreground the 
materiality of the medium "is to unsettle the frontier between subject and object, figure and ground". ${ }^{11}$ Such unsettling is important, Beugnet says, because it challenges the "representation of the self as a separate entity." 12

Reconfiguring the centrality of the figure or subject in film forces us to confront versions of ourselves that are less important and even less autonomous. We become humans in the periphery. Such selves are stripped bare; embodied illusions of a grand and certain past with its misplaced memories of the clear borders between me and you, us and them, and what is and what is not. Beugnet herself describes the lack of familiarity with what we see in film as a place where the "moving image is not merely ... in the service of a discourse, but a discourse in itself - and an embodied one at that." 13 These are invaluable words for the collection of diffuse practices and influences that we call on as being screendance. For all our efforts (as artists and scholars in the field of screendance) to make claims for and on behalf of others-to make screendance the figure and subject-it is the uncertain and embodied moving images on the periphery, on the edges of what we can take notice of and understand, that fuel this field. They are the experiments - in writing, moving, and filming - that both define and undermine our identity. Such a diffuse identity is a place of both precarity and strength.

But as our contributing authors show, ambiguity is not without consequence; it is a stance, not a solution. The articles in this volume, which span television drama, documentary, online dance criticism, and Hollywood films, all weave a consideration of ethical (um)mooring in these fields of representation throughout their overall inquiry.

Anthea Kraut turns to Hollywood's archives to uncover the history of the "dance-in," the uncredited dancing doubles that stand-in for celebrities, whose labor props up Hollywood's physical economy, even as they remain unseen. Central to Kraut's analysis of the slippery role dance-ins play is the gendered, racial, and representational politics embedded in the relationships between actress Betty Grable and her long-time dancein Angie Blue, both white, the white choreographer Hermes Pan, and the African American dance coach Marie Bryant. Insofar as the white star performer coheres as an individuated subject, it is because she stands in the place of her predecessors: coaches, captains, and choreographers, as well as her own replacement, the dance-in. All have disappeared behind her image. Tracking the way movement passes from body to body in the Hollywood system, Kraut proposes that we understand this process as both surrogation and recorporealization, and that we "read white star bodies not as autonomous and self-contained but as relational, malleable, and indexical of black corporeality." 14

Hannah Schwadron proposes that we consider screendance scenes within televisual aesthetics, by which she means moments of heightened emotion that strategically employ both camera and bodily movement, bringing a more 'artistic' style of visual composition to mainstream audiences. Schwadron argues that screendance scenes can 
support critical transitions within the narrative, and she particularly calls out a kind of "trans-ness" in such moments in Jill Soloway's hit television show Transparent. In Schwadron's essay, body and camera work together to move the characters across time and space in an effort to both reveal and heal cross-generational traumas inherited among Jewish communities and gender and sexual minorities. In the casting of Jeffrey Tambor as Maura, however, Schwadron encourages us to consider the ethics of what she calls "trans-face," and how it sits within a longer history of Jewish participation in American minstrelsy. This history, and what Schwadron describes as a "murky middle ground" that conflates "Jewish and transgender stories"15 requires us to grapple with how to ethically represent transgendered characters on screen-a charge that becomes more pronounced in light of Tambor's alleged sexual harassment of transwomen on set.

Megan Quinlan analyzes the celebrated documentary film Mr. Gaga, asking how the film's framing of Israeli choreographer Ohad Naharin as "exceptional" obscures or excuses his questionable and even abusive behavior. While documentary films never present an unbiased view of their subjects, Quinlan contends that dance sequences are employed to change the mood, redirect attention, or offer sensationalism rather than confront some of the more uncomfortable aspects of Naharin's style. This not only has the effect of undermining any criticality, it forcibly decontextualizes and depoliticizes Naharin's work. Naharin's exceptionalism comes to a head with the revelation late in the film that the story he tells of how he came to dance-through a desire to communicate with his twin, who did not speak - is a fabrication. Quinlan argues that this narrative epitomizes Naharin's relationship to his choreography, "which he similarly views as unstable and constantly available for revision." ${ }^{16}$ Rather than accede to Naharin's "playful" approach to truth, however, Quinlan weighs the value of this story in a posttruth era.

Kate Mattingly discusses the changing landscape of dance criticism, and how this discourse has moved online. She analyzes three different dance writing platforms and the values espoused by their authors. Pushing against the notion that digital technologies erode the level of discussion by opening the field to more voices, Mattingly challenges the prestige of so-called "canon criticism" in favor of more inclusive models of dance writing. She draws our attention to regimes of value in what she calls the "choreographic apparatus" of dance criticism, which is to say, the ways dance criticism has historically established the terms, concepts, and frames for discussing and evaluating dance. In contradistinction, she offers a consideration of dialogical digital platforms that host multiple voices and perspectives, including those of the artists themselves. In so doing, Mattingly calls upon readers to critically examine the role and position of the dance critic, reconfiguring criticism as a shared activity that “organizes, nurtures, and promotes creative work...in a symbiotic relationship with contemporary performance." 17 
Each of the articles in this volume prompts us to consider the value and values of screendance practices as we move forward as a field. The provocations have more of a retrospective take.

In her provocation, Katja Vaghi turns our attention back to the first volume of IJSD and its claim that screendance has not yet been invented. But times have changed for Vaghi and she now understands the field to be in rare (and independent) health, with higher education courses, scholarly discourse, and blossoming festivals. Her concern though is that there is a danger in institutionalizing the field and an aesthetic. We asked Claudia Kappenberg, who was co-editor of Volume 1, to respond to Vaghi's provocation. In her response, Kappenberg suggests that screendance's strength is in its incompleteness; that we will always be inventing it "over and over again." 18 She imagines that screendance will be less concerned with its form and history, and will start to look outwards to the politics and experiences that help us understand our lives and practices.

We also asked Erin Brannigan and Sherril Dodds to write brief provocations for this volume. Both are strongly connected to screendance writing and scholarship, and both remain key figures in how it is that we might look at and understand screendance practice. Brannigan evocatively blends her deep connection to early 21 st century screendance curation, personal memories, experimental film, and the expansion of choreography from dancing. It's playful, serious and surprisingly poignant. Dodds takes a more direct route and looks into what happens when we call something screendance; that how we look changes what we see, and that this transformation shapes the field itself.

Incoming co-editor Marisa Zanotti uses her provocation to think through how screendance has changed in the last 10 years. She writes of the technology (both the tools we use and the spaces we present in and on), the expansion of screendance practices, and economies of time and space. She finds herself questioning the speed at which she is working, but is also nourished by the potential of more complex "mediated bodily experiences." ${ }^{19}$

Co-editor Simon Ellis interviews IJSD's founding co-editor Doug Rosenberg to get his take on the field since Volume 1 in 2010. Rosenberg wonders about the tendency to prevaricate in scholarly writing, and states his preference for manifesto-driven writing. He sees manifestos as being capable of driving change, and in the interview he also reveals a certain restlessness with the field in which films that are more experimental are swamped by the volume of films that maintain the status quo.

Co-editor Harmony Bench interviews the choreographer Sarah Elgart about her work in and around screendance, particularly her column ScreenDance Diaries with the Los Angeles online magazine Cultural Weekly. Elgart describes her history and work across 
commercial and arts sectors, and the important role screendance plays in the cultural and movement literacies of the contemporary moment.

There are five reviews in this volume of IJSD. Katrina McPherson reviews the 2018 edition of Light Moves Festival of Screendance in Limerick and is particularly struck by the screening of Dziga Vertov's Man With A Movie Camera (1929) with a newly commissioned score by Neil O'Connor and Dunk Murphy. Xiomara Forbez reviews Colleen Dunagan's Consuming Dance: Choreography and Advertising and notes the extent to which the advertising world embraces or perhaps appropriates dance in an attempt to have advertisements become something more than-or other to-just a means to sell something. Kyle Bukhari reviews the volume on Charles Atlas edited by Lauren Wittels, and likes the multi-voiced approach to Atlas's work, including a recent interview especially for the volume with Atlas himself. Elisa Frasson responds to Telory D. Arendell and Ruth Barnes' edited volume Dance's Duet with the Camera: Motion Pictures, remarking on the editors' desire to balance the relationship between the dance and the film. Finally, Robin Gee brings this section full-circle by reviewing the 2nd edition of Katrina McPherson's Making Video Dance. Gee remarks on the key updates of the book, including experimental screendance processes, using scores to develop movement, exercises for teaching, and the companion website.

These then are the last few sentences we will write as co-editors of IJSD. It has been, as you can imagine, rewarding and challenging. In our tenure, we moved the journal from the University of Wisconsin to The Ohio State University and, with an eye toward sustainability, moved it entirely online. We adopted creative commons licensing to ensure that the ideas contained in these pages can circulate without paywalls so as to serve the screendance community at its furthest reaches. We thank Maureen Walsh and the Libraries at OSU for assistance with each of these steps. A heartfelt thank you to authors, reviewers, and copy-editors (in V10 it was Claire Ridge and Carol Breen at CDaRE), to the editorial board for their support, and most of all to people like you who read the journal. It is you that we have tried to keep in mind at all stages of the process, each year. We have tried to make the journal "international" as the IJSD's title states, and recognize that there is still much to do here. As we welcome Kyra Norman and Marisa Zanotti as the incoming co-editors of IJSD, we hope they will achieve greater success in this area than we have. After five years as co-editors, we are anxious to see what will unfold under their stewardship. We leave Kyra and Marisa with a journal that has tried to be as malleable and fluid as screendance itself, and we look forward to cheering from the sidelines as they draw the journal and its readers and contributors into a next generation with different tones, possibilities, insights, and practices. It has truly been a pleasure to serve this community. 


\section{Biographies}

Harmony Bench is Associate Professor in the Department of Dance at The Ohio State University. From 2014-2019, she has been co-editor of The International Journal of Screendance with Simon Ellis. She is currently at work on a collaborative research project with Kate Elswit, funded by the Arts and Humanities Research Council, which brings data visualization and computational tools of analysis to bear on dance history in the study of mid-century African American choreographer Katherine Dunham. https://dunhamsdata.org/.

\section{Email: bench.9@osu.edu}

Website: http://www.harmonybench.com

Simon Ellis is a choreographer, dancer, and film-maker. He is from New Zealand but now lives in London, and is an Associate Professor at the Centre for Dance Research at Coventry University. He is particularly interested in the limits and possibilities of collaboration in choreographic processes.

Email: simon.ellis@coventry.ac.uk

Website: http://www.skellis.info

\section{Notes}

${ }^{1}$ Harmony Bench and Simon Ellis, International Journal of Screendance Volume 10:

"Screendance Now" Open Call For Papers.

${ }^{2}$ Harmony Bench and Simon Ellis (eds). "Community and Screendance."

${ }^{3}$ Douglas Rosenberg, Screendance, 117.

${ }^{4}$ Rushkoff, Team Human, Chapter 41 (no page number).

${ }^{5}$ Jerome Bruner, The Culture of Education, 3.

${ }^{6}$ Brian Eno, A Year With Swollen Appendices, 317.

${ }^{7}$ Hamish MacPherson, What Are Screendance Competitions Even For?, 180.

${ }^{8}$ Hans-Jörg Rheinberger, Forming and Being Informed, 204.

${ }^{9}$ Idem, 203.

${ }^{10}$ Martine Beugnet, Cinema and Sensation, 14. 
${ }^{11}$ Idem, 63.

12 Ibid.

${ }^{13}$ Idem, 59.

${ }^{14}$ Anthea Kraut, "The Dance-In," 34.

${ }^{15}$ Hannah Schwadron, "Trans-Screens of Gender and Jewishness," 64.

${ }^{16}$ Meghan Quinlan, "Mr. Gaga," 88.

${ }^{17}$ Kate Mattingly, “Digital Dance Criticism,” 100.

${ }^{18}$ Claudia Kappenberg, "A Note Towards," 134.

${ }^{19}$ Marisa Zanotti, “Digital Spaces," 152.

\section{References}

Bench, Harmony and Ellis Simon (eds). "Community and Screendance": International Journal of Screendance Volume 5" (2015). https://doi.org/10.18061/ijsd.v5i0

. "International Journal of Screendance Volume 10: 'Screendance Now' Open Call For Papers" 21 May 2018.

https://screendance.wordpress.com/2018/05/21/international-journal-ofscreendance-volume-10-screendance-now-open-call-for-papers.

Beugnet, Martine. Cinema and Sensation: French Film and the Art of Transgression. Edinburgh: Edinburgh Univ. Press, 2007.

Bruner, Jerome. The Culture of Education. Harvard University Press, 1996.

Eno, Brian. A Year with Swollen Appendices. London: Faber and Faber, 1996.

Kappenberg, Claudia. "A Note Towards." The International Journal of Screendance 10 (2019). https://doi.org/10.18061/ijsd.v10i0.6653

Kraut, Anthea. "The Dance-In and the Re/production of White Corporeality." The International Journal of Screendance 10 (2019).

https://doi.org/10.18061/ijsd.v10i0.6514

MacPherson, Hamish. "What Are Screendance Competitions Even For? A Response to the 2015 Leeds International Film Festival Screendance Competition." The International Journal of Screendance 6 (2016). https://doi.org/10.18061/ijsd.v6i0.5063 
Man With A Movie Camera. Dir. Dziga Vertov. Film. Soviet Union. 1929.

Mattingly, Kate. "Digital Dance Criticism: Screens as Choreographic Apparatus." The International Journal of Screendance 10 (2019).

https://doi.org/10.18061/ijsd.v10i0.6524

Quilan, Meghan. "Mr. Gaga: Embodying the Exceptionalism of Ohad Naharin." The International Journal of Screendance 10 (2019).

https://doi.org/10.18061/ijsd.v10i0.6525

Rheinberger, Hans-Jörg, and Michael Schwab. 'Forming and Being Informed'. In Experimental Systems: Future Knowledge in Artistic Research, 198-219. Orpheus Institute Series. Leuven: Leuven University Press, 2013.

Rosenberg, Douglas. Screendance: Inscribing the Ephemeral Image. Oxford and New York: Oxford University Press, 2012.

Rushkoff, Douglas. Team Human. New York: W.W. Norton \& Company, Inc, 2019.

Schwab, Michael (ed). Experimental Systems: Future Knowledge in Artistic Research. Leuven: Leuven University Press, 2013.

Shwadron, Hannah. "Trans-Screens of Gender and Jewishness in Jill Soloway's Transparent: Post-Network TV and the Screendance Scene." The International Journal of Screendance 10 (2019). https://doi.org/10.18061/ijsd.v10i0.6522

Zanotti, Marisa, "Digital Spaces, Analogue Thinking: Some Thoughts on Screendance." The International Journal of Screendance 10 (2019).

https://doi.org/10.18061/ijsd.v10i0.6569 